\title{
Modelling and Speed Control of Permanent Magnet Brushless DC Motor using PID
}

\author{
${ }^{* 1}$ Sonali Rangari, ${ }^{2}$ Gunwanti Shende, ${ }^{3}$ Preeti Kapoor \\ ${ }^{1,2,3}$ Shri Ramdeobaba College of Engineering and Management, Nagpur \\ Email: ${ }^{1}$ rangaris@rknec.edu, ${ }^{2}$ shendegs@rknec.edu, ${ }^{3}$ kapoorpv@rknec.edu
}

Received: 06th October 2019, Accepted: 20th November 2019, Published: 31st December 2019

\begin{abstract}
Trapezoidal flux distributed Permanent Magnet Brushless DC motor (PM-BLDC) has several advantages as compared to conventional DC and AC motor such as high speed, low weight-to-power ratio, high speed, electronic control, and low maintenance. The PM-BLDC motor also known as electronically commutated motor. Day by day usage of PMBLDC motor is increasing, so it is necessary to implement the control technique to control the motor performance parameter like torque, speed. This paper presents a modelling and speed control of three phase PM-BLDC motor. Modelling of PM-BLDC is derived with circuit equation and developed in MATLAB/Simulink model. The speed control strategy is tested on PM-BLDC motor and their performance is evaluated. This paper also shows that by using close loop strategy it is possible to control speed, torque, and rotor angle theta as per requirement.
\end{abstract}

\section{Keywords}

PM-BLDC, PID, VSI, Simulink Model, Back EMF.

\section{Introduction}

Permanent Magnet Brushless Motors has two types namely Permanent Magnet Synchronous Motor (PMSM) with a flux distribution is sinusoidal, and Permanent Magnet Brushless DC motor (PM-BLDC) with trapezoidal flux distribution. The PM-BLDC motor has a number of advantages over induction motors and brushed dc motors. There is less energy wastage in permanent magnet DC motor, hence the efficiency is very high. These motors have highly reliable with light weight, high torque handling capability, less maintenance and less noise. Due to mentioned advantages the motors are used in various applications such as HVAC, automotive, electronic, medical industries and electric vehicles PM-BLDC motor has trapezoidal back EMF, because of the non-sinusoidal dispersal of the self and mutual inductances in the middle of stator and rotor. There is no specific advantage in conversion of the ' $a-b-c$ ' equations of the PM-BLDC to the $d-q$ form. Hence the solution of the original ' $a-b-c$ ' equations is proposed for the PM-BLDC motor [1]. The PM-BLDC motor can be categorized as an electronically commuted motor. With the help of rotor position electronically commutation is performed for PM-BLDC motor. As the rotor position changes simultaneously the polarity of the stator winding is also changed. This is performed by semiconductor switches which are to be switched in synchronization with the rotor position; this operation of motor improves its operating speed and area of applications. Due to rotation of rotor voltage is induced in the stator winding known as back-EMF of PMBLDC motor. So ideally, torque is primarily influenced by back-EMF of PM-BLDC motor. But practically the torque ripple exist mainly due to imperfection of back EMF, ripple of current and phase current commutation and the imperfection EMF is occurred due to the magnet size and shape of the PM-BLDC motor.This paper shows the modelling of PM-BLDC motor based on a-b-c equations of the PM-BLDC motor.

\section{Methodology}

\section{A: Modelling of PM-BLDC Motor}

In PM-BLDC motor the flux distribution is trapezoidal and therefore the $d-q$ axis rotor reference frames model derived for the permanent magnet synchronous motor cannot be applied. Due to The nonsinusoidal flux distribution, it is preferred to do modelling of the PM-BLDC motor in phase variables. Mathematical Modelling of PM-BLDC motor has following assumptions that are, [11][4]

a. Due to stator harmonic fields, the induced rotor currents are neglected.

b. Stray and Iron losses both are neglected.

c. Assuming the three phases are symmetric, the rotor reluctance does not change with angle. The selfinductance and the mutual inductance of three phases are equal to each other and they are symbolized as $L a a=L b b=L c c=L^{\prime}$ and $L a b=L b a=L a c=L c a=L b c=L c b=M$. Henry and $L^{\prime}=L^{\prime}-M$ Henry

d. The rotor resistance of all phases is equal i.e. $R a=R b=R c=R . \Omega$

e. $I a+I b+I c=0$ 
Damper windings are not present in PM-BLDC motor and so the damping in this motor is provided by using the inverter control. The three phases motor is considered for the modelling and the derivation can be extended for any number of phases hence for any number of phases the derivation procedure is authentic. The equations of the stator windings in terms of motor parameters are given as

$V a=R a I a+L a a \cdot \frac{d I a}{d t}+L a b \cdot \frac{d I b}{d t}+$ Lac. $\frac{d I c}{d t}+E a$

$V b=R b I b+L b b \cdot \frac{d I b}{d t}+L b a \cdot \frac{d I a}{d t}+L b c \cdot \frac{d I c}{d t}+E b$

$V c=R c I c+L c c \cdot \frac{d I c}{d t}+L c a \cdot \frac{d I a}{d t}+L c b \cdot \frac{d I b}{d t}+E c$

Current can be written as

$I a=\frac{1}{3 L} \int(2 * V a b+V b c-2 * E a+E b+E c-3 * I a * R)$

$I b=\frac{1}{3 L} \int(-V a b+V b c+E a-2 * E b+E c-3 * I b * R)$

$I a+I b+I c=0$

$\therefore I c=-(I a+I b)$

Where,

Phase voltages of a. $\mathrm{b}$ and $\mathrm{c}$ are $V a, V b, V c[V]$.; Stator current of phases $\mathrm{a}, \mathrm{b}$ and $\mathrm{c}$ are $I a, I b, I c[A]$; whereas Back EMF of phase a, $\mathrm{b}$ and $\mathrm{c}$ are $E a, E b, E c[V] ; L$ - per phase self-inductance of each phase (L'-M) $[H] ; R$ - per phase armature resistance of each phase $[\Omega]$.

$T_{e}=\frac{(E a . I a+\quad . I b+E c . I c) \cdot 1}{\omega_{m}} \mathrm{~N}-\mathrm{m}$

Also $T e=\frac{P}{2} . \emptyset a b c . I a b c$

In the above equations as $\Phi a b c$ is function of $\Theta_{\mathrm{r}}$ we get rippling torque and the instantaneous-value of induced EMFs can be written as

$E a=f\left(\theta_{r}\right) . \varnothing \cdot \omega_{m}$

$E b=f\left(\theta_{r}-\frac{2 \pi}{3}\right) \cdot \emptyset \cdot \omega_{m}$

$E c=f\left(\theta_{r}+\frac{2 \pi}{3}\right) \cdot \varnothing \cdot \omega_{m}$

Where the functions $f\left(\theta_{r}\right), f\left(\theta_{r}-\frac{2 \pi}{3}\right)$ and $f\left(\theta_{r}+\frac{2 \pi}{3}\right)$ have the similar shape as Back EMF Ea, Eb and Ec with a minimum and maximum value of \pm 1 . The induced EMFs have rounded edges instead of having sharp edges as shown in fig. 3. Since the EMFs are the imitative of the flux linkages derivatives. The flux linkages are continuous function. The flux density functions smooth with no immediate verges due to fringing.

For a normal system, the equilibrium equation of motor with friction coefficient ' $B$ ', inertia ' $J$ ', and load torque ' $T l$ ' is

$T e-T l=J \cdot \frac{d \omega_{m}}{d t}+B \omega_{m}$

Where $\omega_{m}$ is the frequency of rotor in $\mathrm{rad} / \mathrm{sec}$. The relation of the electrical rotor speed and position is given by equation (9)

$\frac{d \theta_{r}}{d t}=\frac{P}{2} * \omega_{m}$ 
Where, $\mathrm{P}$ is the no. of pole, $\Theta_{\mathrm{r}}$ is the rotor position in radians and $\omega_{\mathrm{m}}$ is the mechanical rotor speed in $\mathrm{rad} / \mathrm{sec}$.

As the rotor starts rotating the rotor angle $\Theta_{\mathrm{r}}$ begins to change and EMF get induced in the stator windings (trapezoidal). For smooth rotation of rotor, the stator windings are supplied by square waved current. The position of rotor is sensed by Hall Effect sensor and according to the sequence of winding excitation Hall Effect sensor are switched to get smooth rotation of rotor. [10,2,3]

\section{B. Explanation of Block Diagram:}

Representation of mathematical equation to formulate the modelling of PM-BLDC motor is shown in fig.1. With the block diagram each block of PM-BLDC motor can be represented by mathematical equation as mention in section II. The PID controlled voltage source is feeding the DC link supply to three phase inverters. The output of inverter is controlled AC voltage which is given to the motor and current start to flow in the stator winding having constant impedance. As the current flows through the winding, the net effective self and mutual inductances of winding gives the flux in the winding. Flux in the stator depends on the number of conductors placed in the stator slots, flux density, length of conductors, radius of the rotor bore, and airgap between rotor and stator.

Because of the damper winding is not present and the rotor movement is controlled by hall sensor in the PM-BLDC motor, the flux is considered as a constant for definite rotation. By closely analysing the motor, rotor's North Pole get locked with stator for very short duration of time where constant flux obtain otherwise flux is linearly increasing or decreasing. Therefore, the flux is a function of rotor angle Or. After flux is produced magnetic field sets up and the current carrying windings pull the rotor in forward direction. The electromagnetic torque produced in the motor is the product of flux and current. As rotor starts rotating the back EMF is induced in the winding which overall affect the supplied voltage and current of the motor. [5][9]

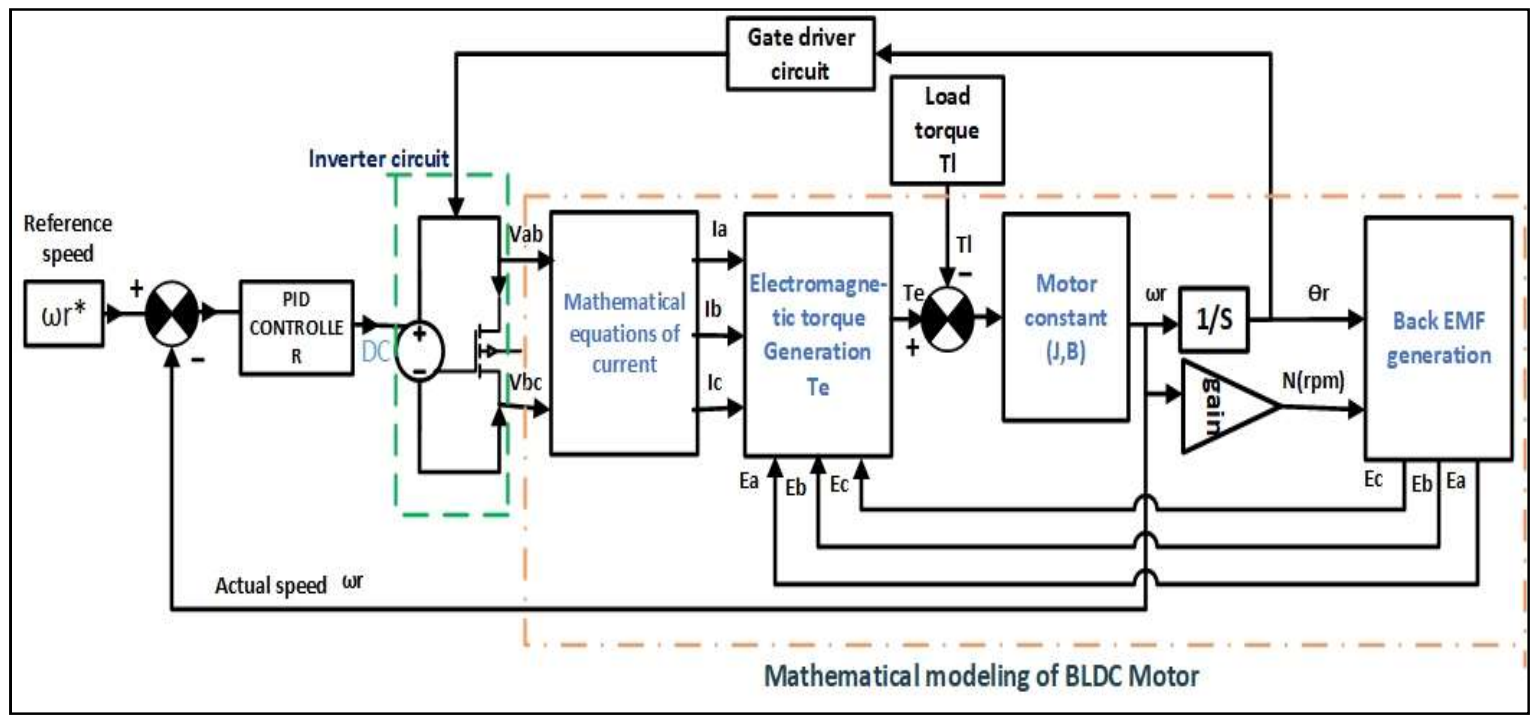

Fig.1: Schematic Diagram Modelling of PM-BLDC Motor

To get the variable speed, variable torque performance of the PM-BLDC motor PID controller in a close loop is used, which controls the supply voltage of motor through inverter circuit and maintain the speed of motor on desired speed. The inverter switches are triggered by gate driver circuit which generate pulses according to the rotation of rotor i.e. value of rotor angle Or.

\section{Simulation Results:}

The MATLAB Simulink model of PM-BLDC motor is represented as per the block diagram and mathematical equation shown in section II. The MATLAB model of PID controlled PM-BLDC motor is simulated for the motor parameter shown in Table I at variable speed constant torque condition. The drive is also simulated for constant speed and variable torque condition. The various performance characteristics of the drive are recorded and presented subsequently from fig 2-6.The speed of the motor is obtained at various load conditions. The desired speed is obtained by close loop system. PID controller is used to maintain the DC supply of inverter according to the loading conditions. [6-8] 
Fig. 3(b) shows rotor speed variation of $800 \mathrm{rpm}$ and $1000 \mathrm{rpm}$ at $0.2 \mathrm{sec}$ and at $1 \mathrm{sec}$ respectively for torque constant control method. Similarly the same figure shows load torque $2 \mathrm{~N}-\mathrm{m}$ and $5 \mathrm{~N}-\mathrm{m}$ at $1 \mathrm{sec}$ and $1.5 \mathrm{sec}$ for speed constant control method.

\begin{tabular}{|l|l|l|}
\hline Sr No & Motor Parameter & $\mathbf{2 2 0 V}, \mathbf{1 0 0 0} \mathbf{~ r p m}$ \\
\hline 1 & Stator Phase Resistance (R) & $2.87 \Omega$ \\
\hline 2 & Stator Phase Inductance (L) & $9.5 \mathrm{mH}$ \\
\hline 3 & Motor Inertia (J) & $0.0008 \mathrm{Kg}-\mathrm{m} / \mathrm{sec}^{2}$ \\
\hline 4 & Motor Viscous Damping (B) & 0.001 \\
\hline 5 & Pole Pair $(\mathrm{P})$ & 8 \\
\hline 6 & Flux Linkage $(\Phi)$ & $0.175 \mathrm{wb}$ \\
\hline
\end{tabular}

\section{Table 1: Motor Parameters}

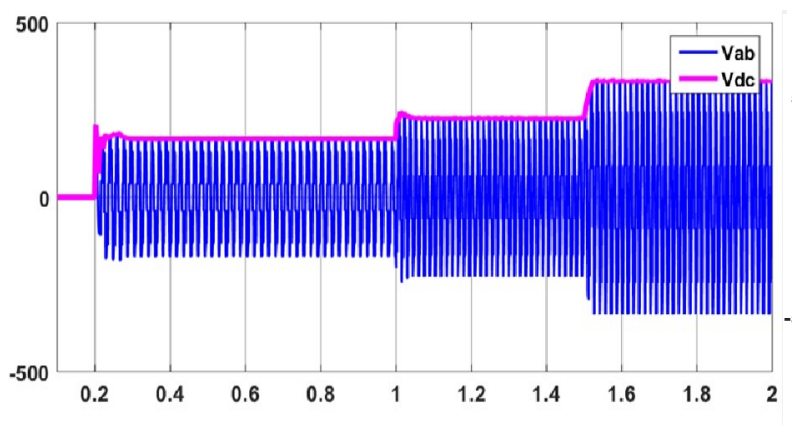

Fig.2 (a): DC Voltage Supplied to Motor.

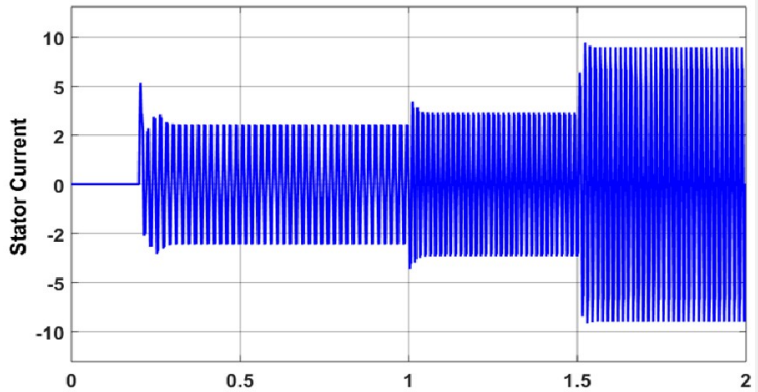

Fig.3 (a): Stator Current Ia of the Motor.

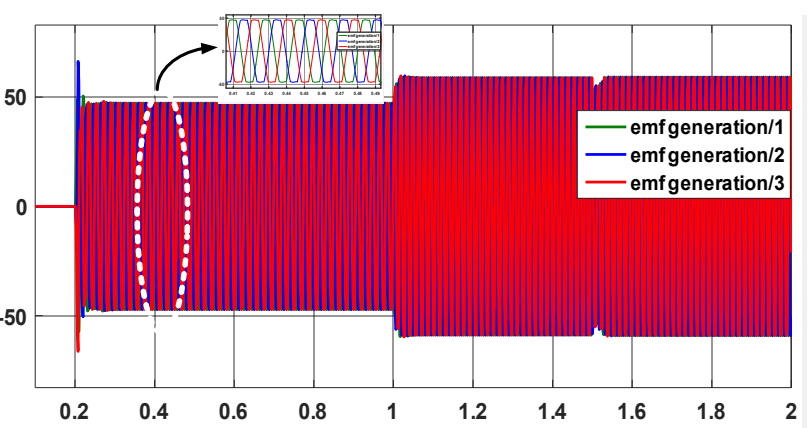

Fig.2 (b): Back EMF Induced in the Motor.

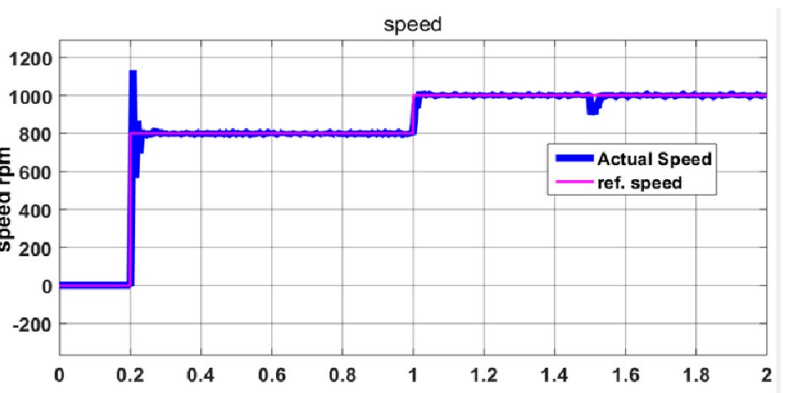

Fig.3 (b): Speed in rpm of Motor.

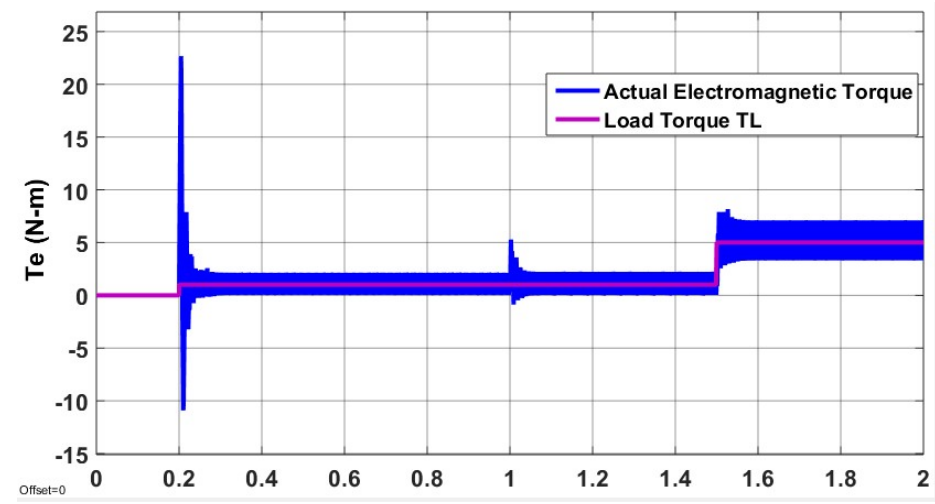

Fig.4: Electromagnetic Torque and Load Torque of Motor

Fig 2(a) shows the DC voltage supplied to the motor thorough PID controller at different load condition. Fig.2 (b) shows the back EMF generated in the Motor and Fig 3(a) shows the variation of stator current at different load 
condition. Given results shows that the when torque is constant variation of speed is possible (see fig 2(b)), also when load torque is varied (up to $5 \mathrm{~N}-\mathrm{m}$ ) then speed can maintain constant by using PID controller which adjusted the supply voltage Vdc for required output. Hence the voltage of motor is controlled simultaneously current and back EMF is also varied accordingly.

\section{Conclusion}

This paper presents the modelling and performance of three phase PM-BLDC motor at variable load condition. From the results it is found that this controller can very well work for variable speed and variable torque. It can be concluded that by using close loop strategy it is possible to control speed, torque, and rotor angle theta. The motor performance i.e. DC voltage, back EMF and stator current, speed and torque vary proportionally with desired performance. The Torque handling capacity of PM-BLDC motor is high. For the desire operation and control, use of PID controller is suitable for medium power drive system. The modelling method can be extended to any number of phases.

\section{References}

1. Paragsen pillay and Ramu krishnan. 1989. Modelling, Simulation, and Analysis of Permanent-Magnet Motor Drives, Part 2: The Brushless DC Motor Drive. IEEE transactions on industry applications.

2. Vinod Kr Singh Patel, A. K. Pandey. 2013. Modelling and Simulation of Brushless DC Motor Using PWM Control Technique. International Journal of Engineering Research and Applications (IJERA) ISSN: 2248-9622.

3. Mohammad Mahdi Momenzadeh, Abdullah Fathi Ahmed, Amr Tolba. 2013. Modelling and Simulation of The PM-BLDC Electric Drive System Using SIMULINK/MATLAB for a Hybrid Vehicle.

4. Hemchand Immaneni. 2013. Mathematical Modelling and Position Control of Brushless Dc (PM-BLDC) Motor. International Journal of Engineering Research and Applications (IJERA) ISSN: 2248-9622.

5. A. Purna Chandra Rao, Y. P. Obulesh and Ch. Sai Babu. 2012. Mathematical modelling of PM-BLDC motor with closed loop speed control using PID controller under various loading conditions. ARPN Journal of Engineering and Applied Sciences ISSN 1819-6608.

6. Ritesh Keshri, Syamnaresh Garlapati, Alberto Tessarolo and Giuseppe Buja. 2014. Torque Capabilities of a FivePhase PM PM-BLDC Drive vs. a Three-Phase One and Various Supply Modes. IEEE.

7. Balogh Tibor, ViliamFedák, František Durovský. 2011. Modeling and Simulation of the PM-BLDC Motor in MATLAB GUI. IEEE.

8. Priyanka C P, Sija Gopinathan. 2013. Modelling and Position Control of Five Phase Brushless DC Motor. International Journal of Engineering Research \& Technology (IJERT) ISSN: 2278-0181.

9. Sree Lekshmi.T and Shalu George. 2014. MBCET Common Mode Voltage Reduction with Harmonics Study using different PWM Techniques for a Three Phase \& Five Phase PM-BLDC motor. International Conference on Advances in Green Energy (ICAGE).

10. PERMANENT MAGNET BRUSHLESS DC MOTOR DRIVES AND CONTROLS by Chang-liang Xia Tianjin University, P.R. China.

11. Permanent Magnet Synchronous and Brushless DC Motor Drives by Ramu Krishnan. 